\title{
A DIMENSÃO EDUCATIVA NO ESTÁGIO SUPERVISIONADO EM SERVIÇO SOCIAL: A PERSPECTIVA DO SUPERVISOR DE CAMPO
}

\author{
THE EDUCATIONAL DIMENSION IN THE SUPERVISED STAGE IN SOCIAL
}

WORK: THE PERSPECTIVE FROM THE FIELD SUPERVISOR

Adriana Giaqueto ${ }^{1}$

\begin{abstract}
Resumo
Este artigo, resultado parcial de pesquisa desenvolvida na UNESP/Franca, aborda a visão dos supervisores de campo em relação à dimensão educativa inerente à supervisão de campo em Serviço Social. A matéria-prima da supervisão em Serviço Social é o agir profissional, que na perspectiva da totalidade, compreende não só a estratégia de ação, os instrumentos, mas todo o processo de ensino-aprendizagem, análise da realidade, fundamentos teórico-metodológicos, ético-políticos e técnico-operativos; configura-se como um espaço fecundo de construção de mediações. Considerando o Serviço Social como um trabalho social, político, histórico, cuja ação profissional cotidiana é direcionada para a construção de uma sociedade efetivamente justa e democrática, podemos compreender o significado do estágio, pois é através dele que o estudante tem a primeira oportunidade de adentrar neste universo. O estágio supervisionado configura-se como um dos componentes fundamentais no processo de formação profissional do assistente social, pois é através dele que se viabiliza o exercício da práxis, a vivência refletida do conteúdo apreendido no meio acadêmico, a articulação da teoria com a prática. Ao atuar enquanto supervisor de campo, o assistente social compartilha com o estagiário, com o supervisor acadêmico e os docentes da unidade de formação, o processo de construção do conhecimento.
\end{abstract}

PALAVRAS-CHAVE: Serviço Social. Dimensão educativa. Estágio Supervisionado. Supervisão de Campo.

\section{ABSTRACT}

This article is a partial result of research that it has developed at UNESP-Franca; it is about the view of field supervisors on the educational dimension inherent to the field supervision in Social Work. The raw material in the supervision in social work is the professional act, which in the perspective of totality, understands not only the action tactics, instruments, but all the process of teaching-learn, analysis of reality, theoretical-methodological, ethical-political and operative-technical; it is a fertile place construction of mediations. Considering, the social work likes as social, political, historical work, whose daily professional action is directed to the building of a just and democratic society effectively, we can understand the meaning of stage, because it is through him that the student has the first opportunity to into in this universe. The supervised stage configures as one the fundamental components in the process professional training of social worker, because it is through it that enables the Praxis exercise, the experience reflected in the content learned in academia, articulation of theory and practice. To

\footnotetext{
${ }^{1}$ Professora Doutora, do Departamento e Programa de Pós-Graduação em Serviço Social da Faculdade de Ciências Humanas e Sociais da UNESP - Campus Franca/SP - Brasil. Líder do Grupo de Estudos e Pesquisas sobre a Dimensão Educativa no Trabalho Social (GEDUCAS). Telefone: 16-37274706. Email: drigiaqueto@gmail.com.
}

Serv. Soc. \& Saúde, Campinas, SP v. 12, n. 2 (16), p. 157-170, jul./dez. 2013 ISSN 1676-6806 
act while field supervisor, the social worker shares with the academic supervisor and the teaching staff, the process of knowledge building.

KEYWORDS: Social Work. Educational Dimension. Supervised Stage. Field Supervision.

\section{INTRODUÇÃO}

Este artigo é resultado parcial de pesquisa desenvolvida na UNESP/Franca, a qual teve como objetivo investigar sobre a compreensão dos supervisores de campo a respeito de seu papel educativo no processo de supervisão de estágio no curso de Serviço Social da UNESP/Franca.

O estudo foi desenvolvido a partir de pesquisa bibliográfica, realizada através do levantamento da produção acadêmico - científica (teses, dissertações) e livros (fontes bibliográficas) sobre a temática; a pesquisa documental, realizada através de consulta aos documentos relacionados ao curso de Serviço Social (atas de reuniões, seminários, estatutos, regimentos, projeto pedagógico, além de documentos relacionados ao processo de supervisão de estágio (relatórios, atas, planos de estágio) e pesquisa de campo.

A realização da pesquisa documental teve como objetivo reconstruir o processo histórico de implantação do novo currículo da UNESP/ Franca, no contexto do debate da ABEPSS, para situar o estágio supervisionado e como o papel de educador do supervisor de campo vem sendo definido e trabalhado neste contexto.

Além disto, realizamos pesquisa através dos planos de estágio de 2009 e 2010, com a participação de duas estudantes bolsistas PIBIC (Programa Institucional de Bolsas de Iniciação Científica), com o objetivo de conhecer a percepção explicitada neste documento a respeito da supervisão de estágio e da dimensão educativa presente na supervisão.

Quanto à pesquisa de campo, nosso universo de investigação foi constituído dos campos de estágio de Serviço Social vinculados à UNESP de Franca e a própria UNESP, especificamente o espaço de formação profisssional do curso de Serviço Social, com destaque para o estágio supervisionado. Realizamos entrevistas semiestruturadas com seis supervisores de estágio, que supervisionam estagiários do curso de Serviço Social da UNESP de Franca. Procedemos a um sorteio dos seis supervisores, entre uma listagem de todos os supervisores de campo dos terceiros e quartos anos. Os dados das Serv. Soc. \& Saúde, Campinas, SP v. 12, n. 2 (16), p. 157-170, jul./dez. 2013 ISSN 1676-6806 
entrevistas foram organizados e analisados através das seguintes categorias temáticas: papel educativo do supervisor de campo, metodologia da supervisão, desafios e facilidades da supervisão de estágio.

Nos limites do presente artigo, iremos enfocar a visão dos supervisores de campo em relação à dimensão educativa inerente à supervisão de campo em Serviço Social, explicitada na pesquisa de campo, através das entrevistas.

A opção pela escuta deste sujeito - o supervisor de campo - justifica-se pela sua participação, ímpar, no processo de formação profissional do estudante de Serviço Social e pela compreensão da dimensão educativa presente na atuação profissional do assistente social, inclusive no desempenho do papel de supervisor de campo.

O trabalho do assistente social é essencialmente educativo, em todos os espaços sócio-ocupacionais, em todos os momentos, em todas as ações. Ao atuar enquanto supervisor de campo, o assistente social compartilha com o supervisor acadêmico e os docentes da unidade de formação, o processo de construção do conhecimento, viabilizando ao estudante estagiário, a vivência da práxis. É somente através do supervisor de campo, que o processo de aprendizagem no Serviço Social pode efetivarse; podemos dizer, portanto, que sem a supervisão de campo, todo o processo de formação profissional em Serviço Social não se completaria, não seria efetivado.

Além disto, o assistente social supervisor de campo desenvolve o trabalho educativo em dois sentidos: é educativo no exercício de seu trabalho, com a população usuária, e é educativo no processo de supervisão. A dimensão educativa presente no exercício do trabalho como um todo, do assistente social, pode servir como conteúdo pedagógico no processo de supervisão de estágio.

Cardoso e Maciel afirmam que "[...] a função educativa é a primeira e essencial [...]" (2000, p.148). Abreu, ainda, afirma que as relações pedagógicas no trabalho do assistente social concretizam-se sob a forma de ação material e ideológica, nos espaços cotidianos de vida e de trabalho de segmentos das classes subalternas (2011, p. 17).

A forma material é expressa pelas condições materiais concretas de existência das classes expropriadas de seus direitos básicos.

Em relação à forma ideológica, comungamos também do pensamento de Abreu (2011), que por sua vez está sustentado na tradição marxista, privilegiando o conceito gramsciano de cultura, entendido em sua vinculação às relações de hegemonia. 
O princípio educativo na formulação gramsciana consubstancia-se na relação entre a racionalização da produção e do trabalho e a formação de uma ordem intelectual e moral, sob a hegemonia de uma classe. Gramsci, em sua crítica sobre essa relação a partir das experiências do americanismo e do fordismo - expressões paradigmáticas da cultura e hegemonia burguesas no capitalismo monopolista - expõe as raízes do seu conceito de cultura como civiltá (modo de vida, de sentir, de pensar e de agir) (ABREU, 2011, p. 14).

Assim, no exercício das dimensões ético-política, técnico operativa e teóricometodológica, o assistente social supervisor de campo desenvolve um trabalho eminentemente educativo.

O supervisor partilha com o supervisionado a responsabilidade pelo processo de ensino aprendizagem. Sob este ponto de vista, o conteúdo não está dado e nem existe pronto e acabado, trata-se de um conteúdo a ser construído de forma conjunta por supervisor e estagiário.

Cabe ao supervisor ser um facilitador do processo de ensino-aprendizagem, através do qual ele educa e é educado, uma vez que se estabelece uma troca de saberes. É preciso, para a execução deste papel, que o supervisor busque permanentemente, competência profissional.

É através do estágio que o estudante adquire postura crítica diante do enfrentamento das diversas expressões da questão social, objeto de estudo e intervenção do (a) Assistente Social, além de apreender os instrumentais da profissão, e vivenciar, no cotidiano profissional, os preceitos do Código de Ética.

\section{A percepção do supervisor de campo a respeito da dimensão educativa no processo de estágio supervisionado}

$\mathrm{Eu}$ acredito que o supervisor de campo tem um papel fundamental na formação do estagiário supervisionado. Porque o supervisor de campo vai proporcionar para o estagiário ao longo do estágio que ele tenha essa aproximação entre teoria e prática. O supervisor acaba tendo uma contribuição muito importante na própria identidade profissional desse estagiário. (Supervisora de campo)

Pudemos constatar que as supervisoras entrevistadas (estamos utilizando no feminino porque todas eram mulheres) consideram a supervisão de estágio como parte de um todo mais amplo, que é a formação profissional do estudante de Serviço Social. Neste contexto, revelaram que um dos principais desafios, porque é recorrente em todos Serv. Soc. \& Saúde, Campinas, SP v. 12, n. 2 (16), p. 157-170, jul./dez. 2013 ISSN 1676-6806 
os depoimentos, está relacionado com a necessidade de aproximação da unidade de formação acadêmica com os campos de estágio.

Ressaltam a supervisão acadêmica como um desafio e também uma perspectiva de melhorar muitas das dificuldades vivenciadas. As Diretrizes Curriculares e Política Nacional de Estágio trazem uma diferença significativa para a formação profissional, destacando em um de seus princípios a indissociabilidade entre estágio e supervisão acadêmica.

Este princípio veio para romper com a visão de que o estágio é de responsabilidade exclusiva do supervisor de campo, conhecido, no senso comum, como "o professor da prática".

A responsabilidade, neste novo ponto de vista, passa a ser do docente supervisor acadêmico, dividida, compartilhada com o supervisor de campo.

Sem a figura do supervisor acadêmico, o processo de estágio supervisionado não se efetiva como deveria e a formação profissional dos estudantes, é obvio, fica prejudicada.

A implantação do novo projeto político pedagógico do curso de Serviço Social configura-se, como podemos concluir, um dos principais desafios, colocado para os supervisores de campo, a comissão de estágio, para os estudantes, para a formação profissional, enfim.

Outro desafio trazido pelas supervisoras de campo, diz respeito à relação teoria/prática e uma delas destaca que o estudante chega ao campo de estágio despreparado em relação a alguns conteúdos referentes à dimensão técnico-operativa.

Vimos que a lacuna existente hoje quanto à questão dos instrumentos e técnicas dos assistentes sociais no Brasil advém de uma incorporação equivocada e não satisfatória da relação teoria e prática na concepção do materialismo históricodialético, uma vez que o Serviço Social avançou quando enfatizou a unidade entre as dimensões da prática interventiva em uma relação dialética, evidenciando a diversidade; todavia, a formação profissional trata a unidade sem levar em conta as diferenças, isto é, não trata as especificidades de tais dimensões.

Por outro lado, as dificuldades advindas da relação teoria e prática poderiam ser mais bem enfrentadas, se houvesse maior diálogo entre a faculdade e os campos de estágio, o que, na visão das supervisoras, está deixando a desejar. 
São destacados os desafios da relação com a chefia, da relação política no campo de estágio, mas reconhecem que são desafios que perpassam o processo de ensino/aprendizagem.

A relação do supervisor com o estagiário é um elemento importante, que pode facilitar ou dificultar o processo de supervisão.

As supervisoras ressaltam, ainda, como desafio, a própria postura profissional, que servirá como referência aos estagiários, a responsabilidade de mostrar como é a profissão, como atua um profissional da área, os valores da profissão, contribuir, enfim, com a formação profissional:

As dificuldades podem ser trabalhadas pelo supervisor de campo, não como empecilhos para a concretização da supervisão de estágio, mas como conteúdo pedagógico, dada à indissociabilidade das dimensões teórico-metodológica, éticopolítica e técnico-operativa. As situações de desafios na intervenção do assistente social podem passar a se configurar conteúdos para a formação profissional, estreitando os laços existentes entre os sujeitos do processo de supervisão de estágio: estagiário, supervisor de campo e supervisor acadêmico - este quando for uma realidade em nossa formação profissional.

O estagiário pode caracterizar-se um aliado nas lutas cotidianas do assistente social, como a luta por espaço físico adequado, luta por ampliação do quadro de assistentes sociais para um atendimento mais digno e com qualidade aos usuários. São desafios postos ao assistente social e consequentemente ao processo de estágio supervisionado que podem ser percebidos e usados como conteúdo do processo de ensino/aprendizagem, quando ambos os sujeitos - estagiário e supervisor de campo buscam estratégias de enfrentamento, de forma conjunta; quando refletem e buscam alternativas de enfrentamento à situação, que à primeira vista é apenas empecilho para a concretização da ação profissional e para a realização do estágio supervisionado.

As supervisoras afirmam, também, que o estagiário é a "ponte" com a universidade, ele traz para o campo de estágio um conhecimento atualizado, incentiva a reflexão constante.

Mesmo com os desafios existentes na relação teoria e prática, as supervisoras destacam que esta é uma busca incessante e sugerem algumas alternativas para fortalecer a relação da teoria com a prática: uma delas é ter como norte o projeto ético político da profissão e outro, viabilizar mais momentos de encontro com a universidade. Serv. Soc. \& Saúde, Campinas, SP v. 12, n. 2 (16), p. 157-170, jul./dez. 2013 ISSN 1676-6806 
Como já foi enfatizado, a supervisão de estágio é um processo educativo; a dimensão educativa é imanente ao processo de supervisão de estágio, é condição, prérequisito para que a supervisão seja concretizada.

Se os sujeitos da supervisão de estágio compreendem o processo como educativo, numa perspectiva de totalidade, com a compreensão no processo de supervisão é construído conjuntamente por todos os seus integrantes, numa relação indissociável da teoria com a prática, o estudante estagiário aprende, assim como o supervisor de campo e o supervisor acadêmico. Se por outro lado os sujeitos deste processo possuem uma concepção fragmentada de que o supervisor de campo é o "professor da prática" e o supervisor acadêmico é o "professor da teoria", de forma desconectada com as demais disciplinas do curso, o estagiário não terá a apreensão da práxis, não conseguirá perceber que a prática é o espaço para se construir a teoria e vice-versa; ou, na melhor das hipóteses, construirá este caminho sozinho, o que não deveria ser a proposta da supervisão de estágio.

Há uma visão - equivocada - de que à Unidade de Formação Acadêmica é responsável pela teoria e à unidade campo de estágio, a prática, como se tais elementos pudessem ser dissociados. Esta visão é explicitada, por exemplo, no discurso "o supervisor de campo é o professor da prática". Fragmenta-se, desta forma, o saber e a construção do saber. Nesta linha de raciocínio, preferimos a expressão "o supervisor de campo é o professor na prática", uma vez que no processo de construção de conhecimento que ocorre na prática, o supervisor de campo é um dos sujeitos deste processo, do qual devem constituir-se também sujeitos construtores de conhecimento, de forma conjunta e indissociável, o supervisor acadêmico e o próprio estagiário.

Nos depoimentos das supervisoras de campo, encontramos uma reflexão referente à postura de não valorização do momento do estágio, como um reflexo do modo como o estágio é considerado pela unidade de formação, da forma como o estágio é concebido, conduzido pela própria unidade de formação.

Não podemos perder de vista, ainda, que esta é uma dificuldade encontrada não só na unidade de formação UNESP/Franca, mas é uma tendência já apontada pela pesquisa avaliativa sobre "A implementação das Diretrizes Curriculares do Curso de Serviço Social", realizada pela ABEPSS em 2006², a qual destaca que uma das dificuldades mais recorrentes em relação ao tratamento dispensado à prática profissional

\footnotetext{
${ }^{2}$ Os resultados desta pesquisa estão publicados na Revista Temporalis, n. ${ }^{o} 14,2007$. Serv. Soc. \& Saúde, Campinas, SP v. 12, n. 2 (16), p. 157-170, jul./dez. 2013 ISSN 1676-6806
} 
nos currículos refere-se a não assunção da centralidade e transversalidade do "ensino da prática" no currículo, já que "este ensino se operacionaliza, prioritária e restritivamente, por algumas disciplinas. Aqui novamente aparece a clara distinção positivista entre disciplinas teóricas e disciplinas práticas, mantendo uma relação de subalternidade de umas sobre as outras” (GUERRA, 2006 apud RAMOS, 2007, p. 167)

A matéria-prima da supervisão em Serviço Social é o agir profissional. $\mathrm{Na}$ perspectiva da totalidade, o agir profissional compreende não só a estratégia de ação, os instrumentos, mas todo o processo de ensino-aprendizagem (teoria e prática), análise da realidade, fundamentos teórico-metodológicos, ético-políticos e técnico-operativos, enfim; envolve a população usuária, o contexto sócio-histórico mais amplo, por ser um espaço fecundo de construção de mediações.

Como este processo de aprendizagem contém uma concepção de educação e de homem, encontra-se na concepção de profissão uma visão de homem atrelada a uma visão teórica do ser social, desencadeando um determinado projeto de ação.

Embora seu projeto de ação busque conquistas relacionadas ao projeto social das classes expropriadas, o assistente social é um trabalhador, do qual se espera que cumpra, na divisão sócio-técnica do trabalho capitalista, determinadas funções para responder às demandas do poder dominante.

Nesta linha de raciocínio, o trabalho profissional do assistente social é desafiado a responder a questões contraditórias que essa realidade impõe e a partir destas questões contraditórias, desempenhar o papel educativo junto com o estagiário.

As supervisoras de campo destacaram em seus depoimentos, a importância da supervisão de estágio, pois a experiência que viveram enquanto estagiárias influenciou o que construíram até hoje como profissionais, e compreendem a responsabilidade na construção da identidade profissional de seus estagiários. Destacam, nesta construção, que o supervisor trabalha com questões teóricas e metodológicas, num momento fundamental da formação profissional, que é quando o estudante se depara com a realidade de intervenção do Serviço Social.

Em relação ao conteúdo que é ensinado, as supervisoras se manifestam que o espaço da supervisão é significativo por não permanecer no plano discursivo, incompatível com a dimensão interventiva da profissão:

O instrumento básico de trabalho do assistente social, a linguagem, envolve atividades que dependem de habilidades como o escutar, mas também decodificar e Serv. Soc. \& Saúde, Campinas, SP v. 12, n. 2 (16), p. 157-170, jul./dez. 2013 ISSN 1676-6806 
traduzir conteúdos estabelecidos nas relações sociais com os sujeitos junto aos quais atua. A escuta é suporte que reforça o caráter político do trabalho do assistente social a partir de sua associação às dimensões teórico-metodológica e técnico-operacional.

Como podemos perceber a compreensão do conteúdo a ser trabalhado na supervisão de estágio, por parte do supervisor de campo, perpassa sua compreensão a respeito deste processo como um todo. Algumas supervisoras entendem o conteúdo da supervisão como apenas prático, ou um complemento da teoria, que é aprendida na faculdade; outras, já percebem este conteúdo como todo o processo vivenciado e refletido no campo de estágio, nas palavras da própria supervisora: "todo processo é conteúdo".

Este entendimento revela que à medida que a supervisão é compreendida como um processo didático-pedagógico, inserido em um contexto maior, ela se caracteriza como um processo de trabalho pedagógico-social, ou seja, deve favorecer a ultrapassagem do singular ao universal, dando ênfase à intervenção que particulariza o Serviço Social no âmbito das relações sociais.

Supervisionar, nesta perspectiva, é construir, junto com o estagiário, estratégias coerentes com o projeto ético-político profissional. Envolve a contribuição, portanto, para o desenvolvimento de visão crítica, do saber problematizar e, consequentemente, investigar, planejar e desenvolver propostas qualitativas, na dinâmica das relações entre Estado e Sociedade Civil.

A supervisão, no contexto da formação profissional, carrega suas contradições e superações, que se expressam diante das exigências e dos desafios contemporâneos à formação e ao exercício profissional.

Questionamos as supervisoras sobre a metodologia utilizada no processo de supervisão de estágio e a escolha pela palavra "metodologia" não é apenas uma questão semântica, mas por compreendermos que a supervisão de estágio faz parte de uma totalidade na formação profissional e o estágio como componente curricular que favorece a relação teoria-prática, compreende uma vivência, em que o "como fazer" não pode vir desvinculado do "porquê" e o "para quê" da ação.

Para o desempenho da supervisão de estágio, uma das supervisoras de campo destaca o processo de estágio como um momento da formação profissional, entendida como um processo contínuo, que não deve se esgotar no tempo da graduação. A formação profissional é aqui compreendida como processo contínuo de Serv. Soc. \& Saúde, Campinas, SP v. 12, n. 2 (16), p. 157-170, jul./dez. 2013 ISSN 1676-6806 
desenvolvimento pessoal, profissional e político-social, que não se constrói em alguns anos de curso, ou mesmo pelo acúmulo de cursos, técnicas e conhecimentos, mas pela reflexão contínua e coletiva do trabalho, de sua direção, de seus meios e fins e durante a carreira profissional.

$\mathrm{Na}$ ação educativa, educador e educando, como seres individuais e sociais interagem no processo de ensino e aprendizagem e é no contexto de relações sociais historicamente definidas que se realiza a ação educativa. Se no estágio o estudante, através da primeira aproximação com a prática profissional, encontra um espaço favorável para que possa refletir sobre sua ação, para entender o seu modo de agir profissional e volte à ação, por entendimentos sucessivamente mais avançados, que possibilitem novas reflexões e ações, desenvolve melhor sua capacidade de compreensão e emergência de níveis de abstração que vão se tornando cada vez mais concretos através do cotidiano vivido. Assim é que o trabalho por ele desenvolvido no estágio pode tornar-se uma fonte de aprendizagem profissional, que não se esgotará neste momento, mas que encontrou um terreno fértil para construir as primeiras bases do conhecimento em relação à práxis profissional.

No campo de estágio desta supervisora, os estagiários têm a oportunidade de terem momentos de supervisão individuais - com o supervisor de campo apenas - e coletivos - com outros estagiários do curso de Serviço Social, bem como com de trabalho interdisciplinar, com outros estagiários de outra área.

Sem dúvida, nesta forma de organização do estágio supervisionado as possibilidades de aprendizagem são enriquecidas pelas trocas, tanto entre estagiários e supervisores do Serviço Social, como entre estes e outros estagiários e supervisores de outra área. Neste campo de estágio, pela fala da supervisora, este momento da formação profissional dos estagiários encontra um terreno repleto de possibilidades para a construção do conhecimento, uma vez que os estagiários podem vivenciar uma proposta de trabalho interdisciplinar e a supervisão de estágio de forma coletiva.

Alguns supervisores trazem a importância do planejamento no processo de supervisão, que desta maneira, torna-se sistematizado, cujos procedimentos são compreendidos por ambos os sujeitos envolvidos:

Interessante pontuar, que três das seis supervisoras entrevistadas, descreveram uma metodologia de supervisão que contempla procedimentos parecidos: há uma preocupação por parte do supervisor em relação às diferenças de experiência, vivência e Serv. Soc. \& Saúde, Campinas, SP v. 12, n. 2 (16), p. 157-170, jul./dez. 2013 ISSN 1676-6806 
bagagem teórica de alunos de terceiro e quarto anos, respeitando-se a individualidade de cada um. Além disto, há um procedimento comum, que é primeiro o estagiário apenas observar a atuação do supervisor e quando estiver preparado, ser observado pelo supervisor e após, atender sozinho, sem a presença do supervisor, que neste caso, estará acompanhando através das reflexões após o atendimento. Esta maturidade de poder atuar sozinho, na fala das supervisoras, nem sempre parte dos estagiários, mas são elas que indicam quando estão preparados, o que também, pelas falas das supervisoras entrevistadas, nem sempre é muito tranquilo para o estagiário, pois a supervisora, dependendo do estagiário, tem que estimular esta iniciativa.

Importante observar, ainda, o respeito para com o usuário, quando a supervisora relata que sempre pede autorização aos usuários atendidos em relação à presença do estagiário. Esta conduta, ao lado de outras, sem dúvida, serve de referência ao estagiário, em relação à postura ética.

Fica evidente através dos depoimentos das supervisoras de campo, que o processo de estágio supervisionado, de fato, oferece ao estagiário a oportunidade de contato com as dimensões teórico-metodológica, ético-política e técnico-operativa. As articulações entre estas dimensões dependem de cada campo, de cada estagiário, de cada supervisor, das articulações com a faculdade e das possíveis relações entre todos estes sujeitos.

Os depoimentos das supervisoras revelam, ainda, que a avaliação também compõe a metodologia de trabalho na supervisão. Como pudemos constatar, além da exigência da faculdade, a avaliação é um procedimento constante, que ocorre no decorrer de todo o processo da supervisão, sendo parte desta formação do estudante, entendida como um componente educativo também. Todas as falas indicam que há uma compreensão da avaliação não como uma imposição de notas, com critérios préestabelecidos pelo supervisor, mas a avaliação faz parte de todo o processo educativo, sendo também um momento educativo, onde o que é avaliado, não é o desempenho do estagiário, mas o processo educativo como um todo. Esta postura foi observada nos seis depoimentos.

A respeito das recentes discussões sobre a formação profissional e a Política Nacional de Estágio, duas afirmaram que não estão acompanhando e não conhecem, duas afirmaram conhecerem vagamente e assim se expressam as supervisoras que têm acompanhado estas discussões e conhecem a Política. 
A Política Nacional de Estágio configura-se um documento elaborado coletivamente, cujo propósito principal, é apresentar diretrizes que visem garantir uma formação e um estágio de qualidade em Serviço Social.

A intensificação da articulação entre as instituições representativas da categoria no tocante a aspectos relacionados à supervisão de estágio se deu em um contexto de precarização do ensino superior, quando contávamos - e ainda contamos - com a ampliação da oferta dos cursos de Serviço Social na modalidade Ensino à Distância (EAD), e grande parte das instituições de ensino tem apresentado uma conduta mercantilista, muitas vezes se furtando dos critérios mínimos para a oferta dos cursos, priorizando aspectos como rentabilidade e não o processo de ensino-aprendizagem.

Neste sentido, A PNE também se constituiu num argumento contra a banalização e precarização da formação profissional, já que os cursos à distância encontram dificuldades profundas para implementar o estágio com qualidade, tal como preconiza o documento. Os cursos presenciais nas esferas privada e pública, por sua vez, com suas particularidades, também têm sido instigados a rever seus procedimentos.

A Política Nacional de Estágio surgiu também logo após a aprovação da Lei Federal de Estágio n. 11.788 e da Resolução 533, responsável pela regulamentação do estágio supervisionado em Serviço Social.

Sabemos que entre a normatização e a realidade dos estágios ainda há uma grande distância, contudo, este foi um grande passo e uma ferramenta importante para todos os sujeitos envolvidos no processo de estágio supervisionado.

A informação sobre a Política e o conhecimento do debate que tem sido realizado sobre estágio supervisionado e formação profissional necessita chegar, como vimos, a todos os supervisores de campo, bem como demais sujeitos deste processo.

\section{CONSIDERAÇÕES FINAIS}

Considerando o Serviço Social como um trabalho social, político, histórico, cuja ação profissional cotidiana é direcionada para a construção de uma sociedade efetivamente justa e democrática, podemos compreender o significado do estágio, pois é através dele que o estudante de Serviço Social terá a primeira oportunidade de adentrar neste universo. O estágio supervisionado configura-se como um dos componentes fundamentais no processo de formação profissional do assistente social, pois é através Serv. Soc. \& Saúde, Campinas, SP v. 12, n. 2 (16), p. 157-170, jul./dez. 2013 ISSN 1676-6806 
dele que se viabiliza o exercício da práxis, a vivência refletida do conteúdo apreendido no meio acadêmico, a articulação da teoria com a prática.

Juntamente com o estagiário, mais do que exercitar instrumentos de atuação, o supervisor reflete com ele sobre os instrumentais, dentro de um projeto de atuação, situado, contextualizado, com objetivos, objeto, metodologia claramente definidos. Toda ação concretiza-se não só através do uso de instrumentos, mas também pelo referencial que a orienta.

O fazer não se caracteriza como apenas um ato, mas é também pensamento baseado em determinada fundamentação teórica e que a ética e o posicionamento político são indissociáveis, uma vez que toda ação representa uma intenção.

Dando voz aos supervisores, pudemos reafirmar a importância do estágio e compreender porque em meio a tantos desafios, estes profissionais continuam buscando contribuir com a formação profissional. São profissionais que conseguem desvelar no cotidiano, muitas vezes, árduo e árido de trabalho, um fazer repleto de possibilidades, ao mesmo tempo em que vão se encantando com os primeiros passos dos profissionais que vão surgindo...

É o educador que não se cansa de aprender enquanto ensina e de ensinar enquanto aprende... Porque o ato educativo é a razão essencial de seu trabalho, em qualquer forma que se apresente.

\section{REFERÊNCIAS}

ABREU, M. M. Serviço Social e a organização da cultura: perfis pedagógicos da prática profissional. São Paulo: Cortez, 2011, p. 14 -17.

ASSOCIAÇÃO BRASILEIRA DE ENSINO E PESQUISA EM SERVIÇO SOCIAL. ABEPSS. Diretrizes Curriculares para o Curso de Serviço Social. In: Coletânea de Leis e Resoluções. Assistente social: ética e direitos. 4. ed. Rio de Janeiro: CRESS, 2004. ABEPSS. Documento base da Política Nacional de Estágio. Brasília, 2009. BRASIL. Lei n. 11788, de 25 de setembro de 2008. Dispõe sobre o estágio de estudantes e dá outras providências. Brasília-DF, 2008.

CARDOSO, F. G.; MACIEL, M. Mobilização social e práticas educativas. In: CFESS/ ABEPSS; CEAD/UnB (Org). O trabalho do assistente social e as políticas sociais. Capacitação em Serviço Social e política social, Brasília: CEAD/UnB, 2000, p. 141-149. Serv. Soc. \& Saúde, Campinas, SP v. 12, n. 2 (16), p. 157-170, jul./dez. 2013 ISSN 1676-6806 
GUERRA, Y. Análise dos Dados da Pesquisa sobre o Estado da Arte da Implementação das Novas Diretrizes Curriculares. Texto produzido para a Oficina descentralizada da ABEPSS “10 anos de diretrizes curriculares - um balanço necessário”, realizada no período de 14 a 16 de agosto de 2006, na Universidade Federal de Juiz de Fora (UFJF) MG e apresentado na Oficina Nacional Descentralizada ABEPSS Regional Leste em 2006.

RAMOS, S. R. A prática na formação profissional em Serviço Social: tendências e dificuldades. Temporalis. Brasília: ABEPSS n. 14, 2007, p. 167.

TEMPORALIS/Revista da Associação Brasileira de Ensino e Pesquisa em Serviço Social - ABEPSS - n. ${ }^{\circ}$ 14, 2007, p. 13-29. 